\title{
DESEMPENHO DO RABANETE SOB DIFERENTES QUANTIDADES E PERÍODOS DE INCORPORAÇÃO DO MATA-PASTO (SENNA OBTUSIFOLIA L.) AO SOLO
}

\author{
João Maciel Barreto FERNANDES ${ }^{1}$ \\ Dalila Regina Mota de MELO ${ }^{2}$ \\ Marcos Vinicius GOMES ${ }^{1}$ \\ Thalisson Pereira de SOUSA ${ }^{1}$ \\ Emílio Bezerra da SILVA ${ }^{1}$ \\ Paulo César Ferreira LINHARES ${ }^{3}$
}

\begin{abstract}
${ }^{1}$ Graduado em Lic. Plena em Ciências Agrárias. Universidade Estadual da Paraíba - Campus IV, Catolé do Rocha - PB. E-mail: joaomaciel.barreto@hotmail.com; marcosvinicius_gomes_17@hotmail.com; thalyssondsouza@hotmail.com; e_b_g_r@hotmail.com;

${ }^{2}$ Doutora em Fitotecnia, professora substituta da Universidade Estadual da Paraíba - Campus IV, Catolé do Rocha - PB. E-mail: dalilaregina@ hotmail.com

${ }^{3}$ Doutor em Fitotecnia, pesquisador da Universidade Federal Rural do Semi-Árido, Mossoró-RN. E-mail: paulolinhares@ufersa.edu.br.
\end{abstract}

Recebido em: 29/09/2014 - Aprovado em: 27/11/2014 - Disponibilizado em: 15/12/2014

Resumo: Espécies espontâneas da caatinga existentes nas áreas de produção constituem-se uma fonte alternativa para serem utilizadas como adubo verde. Portanto, o objetivo deste trabalho foi estudar o desempenho do rabanete sob diferentes quantidades e períodos de incorporação do mata-pasto (Senna obtusifolia L.) ao solo, nas condições edafoclimáticas de Catolé do Rocha-PB. O delineamento experimental utilizado foi o de blocos completos ao acaso com os tratamentos arranjados em esquema fatorial 4 x 3, com três repetições. Os tratamentos consistiram do efeito da combinação de quatro quantidades de mata-pasto $\left(2,7 ; 5,4 ; 7,1 ; 9,8 \mathrm{t} \mathrm{ha}^{-1}\right.$ em base seca) com três períodos de incorporação (14; 28 e 42 dias antes da semeadura). A cultivar utilizada foi Rabanete Branco Comprido (Feltrin). As características avaliadas foram: altura de planta; diâmetro de raiz; rendimento total e rendimento comercial. O melhor desempenho do rabanete foi observado na quantidade de $9,8 \mathrm{t} \mathrm{ha}^{-1}$ e no período de 14 dias de incorporação do matapasto ao solo. O mata-pasto mostrou-se eficiente na avaliação do cultivo orgânico do rabanete.

Palavras-chave: Adubo verde. Agricultura orgânica. Hortaliça.

\begin{abstract}
Spontaneous species of the existent savanna in the production areas are constituted an alternative source for they be used as green fertilizer. Therefore, the objective of this work was to study the acting of the radish under different amounts and periods of incorporation of the forest-pasture (Senna obtusifolia L.) to the soil, in the conditions edafoclimáticas of Catolé do Rocha - PB. The used experimental desing was it of complete blocks at random with the treatments arranged in factorial outline $4 \times 3$, with three repetitions. The treatments consisted of the effect of the combination of four amounts of forest-pasture $\left(2,7 ; 5,4 ; 7,1 ; 9,8 \mathrm{t} \mathrm{ha}^{-1}\right.$ in base it dries) with three incorporation periods (14; 28 and 42 days before the sowing). To cultivate used was Long White Radish (Feltrin). The appraised characteristics were: plant height; root diameter; total income and commercial income. The best acting of the radish was observed in the amount of $9,8 \mathrm{t} \mathrm{ha}^{-1}$ and in the period of 14 days of incorporation of the forest-pasture to the soil. The forest-pasture was shown efficient in the evaluation of the organic cultivation of the radish.
\end{abstract}

Key words: Green manure. Organic agriculture. Vegetable. 


\section{INTRODUÇÃO}

A produção mundial de rabanete está estimada em sete milhões de toneladas por ano, sendo o Japão um dos grandes produtores (ITO; HORIE, 2008). A produção brasileira está estimada em 9.140 toneladas, sendo a maior parte proveniente de propriedades com 2 a 5 hectares (FERREIRA; ZAMBON, 2004).

No Brasil, o rabanete não é considerado atualmente como uma cultura de muita expressão em termos de área plantada e produção. Contudo, é uma cultura de ciclo curto e com elevada rentabilidade (CECILIO FILHO; MAY, 2002).

O rabanete (Raphanus sativus L.) é uma olerícola que tem como característica principal o seu ciclo de produção muito curto. Apesar de não ser produzido em larga escala, torna-se uma alternativa interessante para os produtores em função do seu ciclo e, também, serve como opção para a rotação de cultura. Apesar de ser uma cultura de pequena importância, em termos de área plantada, é importante em grande número de pequenas propriedades dos cinturões verdes. Pode ser usada como cultura "cash" entre outras de ciclo longo, com épocas definidas de plantio, além de ser relativamente rústica e apresentar retorno rápido (MINAMI et al., 1998). É uma espécie exigente em solo fértil principalmente para evitar distúrbios fisiológicos, como rachadura da raiz e podendo responder a doses de adubo orgânico na faixa de 15 a $45 \mathrm{t}$ $\mathrm{ha}^{-1}$ de húmus de minhoca ou esterco bovino curtido (COSTA et al., 2006).

As hortaliças tuberosas por necessitarem de elevadas concentrações de nutrientes e pelo alto custo na adubação química, abre espaço as novas formas de utilização de adubação, como a adubação verde que propicia menor custo de aquisição e maiores benefícios de produção (BATISTA, 2011). Deve-se utilizar como adubação verde, espécies que apresentem boa adaptação às condições edafoclimáticas do local ou região, pois assim favorecem um ambiente livre de doenças com redução do tempo de desenvolvimento nutricional, por tratar-se de espécies que nascem espontaneamente (GOMES, 1984; ESPINDOLA et al., 2004).

As espécies utilizadas como adubo verde devem produzir grandes quantidades de matéria seca, ser resistente ao ataque de pragas e doenças, possuir sementes uniformes e de bom poder germinativo, além de apresentar exigências relativamente baixas quanto ao preparo e fertilidade do solo e ter rápido crescimento e sistema radicular profundo (SILVA et al., 1999).

Entre as espécies utilizadas como adubo verde, se destacam as leguminosas por promover maior benefício ao solo em virtude da fixação biológica de nitrogênio através da simbiose das bactérias existentes em seus sistemas radiculares. No entanto, Favero et al. (2000), afirma que as espécies espontâneas 
podem promover os mesmos benefícios que as espécies introduzidas no que tange a produção de fitomassa e ciclagem de nutrientes.

Desta forma, espécies espontâneas da caatinga vêm sendo estudadas como adubo verde. Linhares et al. (2008) adicionando jitirana (Merremia aegyptia L.) ao solo, observaram efeitos positivos na produção de rúcula. Linhares et al. (2009) estudando o efeito da adubação verde com jitirana

\section{MATERIAL E MÉTODOS}

O experimento foi conduzido na horta didática do Centro de Ciências Humanas e Agrárias da Universidade Estadual da Paraíba - Campus IV, Catolé do Rocha - PB, em solo classificado texturalmente como Franco Arenoso (UFERSA, 2012), no período de junho a agosto de 2012. O município de Catolé do Rocha situa-se a 272 m de altitude, sob as coordenadas geográficas de $6^{\circ} 20^{\prime} 38^{\prime \prime} \mathrm{S}$ e 3744'48”'O. Apresentando um clima, de acordo com a classificação de Koppen, do tipo BSWh', portanto, um clima quente e seco, cuja temperatura média anual é de 27 ${ }^{\circ} \mathrm{C}$.

Antes da instalação do experimento, foram retiradas amostras de solo na profundidade de $0-20 \mathrm{~cm}$, as quais foram secas ao ar e peneiradas em malha de $2 \mathrm{~mm}$. Em seguida, foram analisadas no Laboratório de Fertilidade do Solo e Nutrição de Plantas incorporada ao solo na produção do rabanete, observaram que o tempo de decomposição de sete dias foi o que proporcionou a melhor altura, sendo que as demais características oscilaram entre 21 a 28 dias.

Portanto, o objetivo deste trabalho foi avaliar o desempenho do rabanete sob diferentes quantidades e períodos de incorporação do mata-pasto (Senna obitusifolia L.) ao solo, nas condições edafoclimáticas de Catolé do Rocha-PB.

da Universidade Federal Rural do Semi-Àrido (UFERSA), cujos resultados foram os seguintes: $\mathrm{pH}$ (água 1:2,5) = 8,40; $\mathrm{Ca}=3,74$ cmolc $\mathrm{dm}^{-3} ; \mathrm{Mg}=0,86 \mathrm{cmolc} \mathrm{dm}^{-3} ; \mathrm{K}=122,9$ $\mathrm{mg} \mathrm{dm}{ }^{-3} ; \mathrm{Na}=168,3 \mathrm{mg} \mathrm{dm}^{-3} ; \mathrm{P}=44,2 \mathrm{mg}$ $\mathrm{dm}^{-3}$ e M.O. $=0,09 \%$.

O delineamento experimental utilizado foi o de blocos completos ao acaso com os tratamentos arranjados em esquema fatorial 4 x 3, com três repetições. Os tratamentos consistiram do efeito residual da combinação de quatro quantidades de mata-pasto $(2,7 ; 5,4$; 7,1; 9,8 $\mathrm{tha}^{-1}$ em base seca) com três períodos de incorporação $(14 ; 28$ e 42 dias antes da semeadura).

O preparo do solo consistiu da limpeza manual com enxada, retirada do material para fora da área experimental seguida de uma gradagem e levantamento dos canteiros, realizado manualmente utilizando enxada.

O mata-pasto (Figura 1) utilizado foi coletado de uma área de aproximadamente 1,0 ha nas proximidades do campus IV - UEPB, 
ocupada com plantas que nascem espontaneamente logo que se inicia o período chuvoso, coletadas no período de floração, quando a planta apresenta o máximo de concentração de nutrientes. Depois triturados em máquina forrageira, obtendo-se fragmentos de 2 a $3 \mathrm{~cm}$ de diâmetro, secos ao sol, armazenados em sacos de ráfia com teor de umidade de $11 \%$ para mata-pasto. Foram retiradas cinco amostras de mata-pasto, levadas ao Laboratório de Fertilidade do Solo e Nutrição de Plantas da UFERSA para análise, cuja concentração química de $\mathrm{N}, \mathrm{P}$ e $\mathrm{K}$ para o mata-pasto foi de 17,0;10,2 e 10,0 g $\mathrm{kg}^{-1}$ respectivamente.

Figura 1- Mata-pasto (Senna obtusifolia L.).

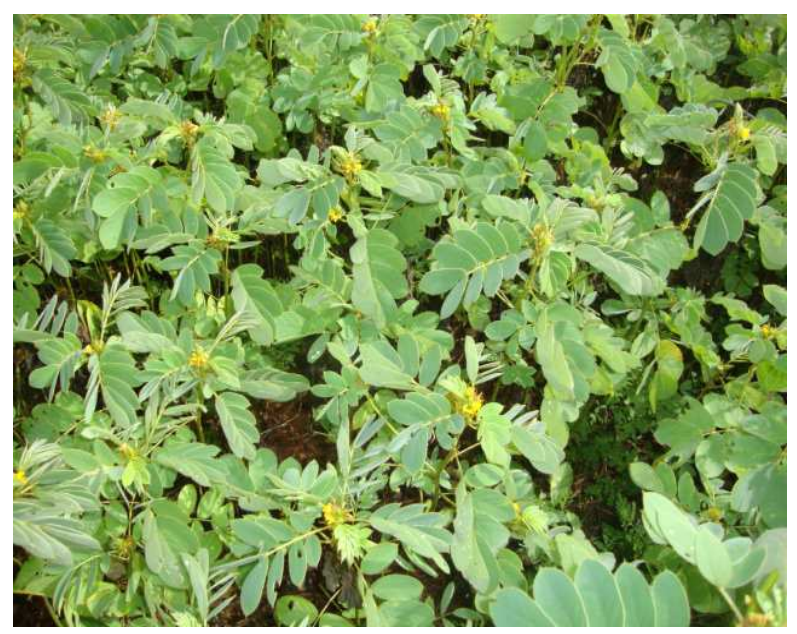

Fonte: MELO, 2012.

Após a incorporação do mata-pasto referente às quantidades e tempos de decomposição, procedeu-se o plantio do rabanete. Cada parcela constou de cinco fileiras de plantas espaçadas de $0,2 \mathrm{~m}$ x 0,05 $\mathrm{m}$ com doze plantas por fileiras, sendo as fileiras laterais e as plantas de cabeceira das fileiras centrais consideradas bordaduras. A área total das parcelas foi de $1,44 \mathrm{~m}^{2} \mathrm{e}$ a área útil de $0,80 \mathrm{~m}^{2}$, contendo 40 plantas.

A cultivar utilizada foi Rabanete Branco Comprido (Feltrin). A propagação do rabanete foi por sementes, no sistema de semeadura direta, efetuando-se o desbaste aos 10 dias após a emergência das plantas (DAE).

As irrigações foram efetuadas por miniaspersão, com turno de rega diária parcelada em duas aplicações (manhã e tarde), durante 15 minutos por turno. Antes da semeadura foram efetuadas irrigações para manter o solo na umidade em capacidade de campo (NOVAES et al., 2007).

A colheita do rabanete foi realizada aos 31 dias após a semeadura. As plantas coletadas foram lavadas e separadas em folhas e raízes. Em seguida, as plantas foram transportadas para o Laboratório de Ecofisiologia vegetal do Departamento de Agrárias e Exatas da UEPB, onde foram avaliadas. Posteriormente, todas as partes das plantas foram preparadas para a avaliação das seguintes características: altura de planta (determinada em uma amostra de quinze plantas, retiradas aleatoriamente da área útil, através de uma régua, a partir do colo da planta até a extremidade da folha mais alta, expressa em centímetro); diâmetro de raiz (determinada através de uma régua milimétrica e expressa em centímetros); rendimento total (determinada a partir da 
massa da matéria fresca das raízes das plantas da área útil, expressa em $\mathrm{kg} \mathrm{m}^{-2}$ de canteiro); rendimento comercial (determinada a partir da massa da matéria fresca das raízes das plantas da área útil livres de rachaduras, não isoporizadas e diâmetros $=20 \mathrm{~mm}$ e, expresso em kg m${ }^{-2}$ de canteiro).

\section{RESULTADOS E DISCUSSÃO}

Neste experimento observou-se interação significativa entre as quantidades de mata-pasto incorporadas ao solo e os seus
Análises de variância para as características avaliadas foram realizadas através do aplicativo software ESTAT (KRONKA; BANZATO, 1995). O procedimento de ajustamento de curva de resposta foi realizado através do software Table Curve (JANDEL SCIENTIFIC, 1991). períodos de incorporação nas variáveis: rendimento total e rendimento comercial. No entanto, não foi observada interação significativa para altura e diâmetro de raízes (Tabela 1).

Tabela 1. Resumo da análise de variância: valores de F para altura de planta (AP), diâmetro de raízes (DR), rendimento total (RT) e rendimento comercial (RC) de raízes de rabanete. Catolé do Rocha-PB, UEPB, 2012.

\begin{tabular}{|c|c|c|c|c|c|}
\hline Causas de Variação & GL & $\mathbf{A P}$ & DR & RT & $\mathbf{R C}$ \\
\hline & \multicolumn{5}{|c|}{---------------------Fatores de F------------------------ } \\
\hline Quantidades de mata-pasto (A) & 3 & $8.05 * *$ & $10,73^{* * *}$ & $53,88^{* *}$ & $162,54^{* *}$ \\
\hline Tempos de decomposição (B) & 2 & $0.75^{\mathrm{ns}}$ & $3,53^{*}$ & $2,14^{\mathrm{ns}}$ & $8,79^{* *}$ \\
\hline A X B & 6 & $1,94^{\mathrm{ns}}$ & $2,44^{\mathrm{ns}}$ & $6,96^{* *}$ & $2,73^{*}$ \\
\hline Testemunha $\mathrm{x}$ Fatorial & 1 & $7,10^{*}$ & $10,73^{* *}$ & $59,77^{* *}$ & $25,38^{* *}$ \\
\hline Tratamentos & 12 & $3,70^{* *}$ & $5,37^{* *}$ & $22,29^{* *}$ & $45,58^{* *}$ \\
\hline Blocos & 2 & 2.92 & 0,13 & 0,18 & 5,05 \\
\hline Resíduo & 24 & --- & ------- & $\begin{array}{l}------- \\
\end{array}$ & ------ \\
\hline $\mathrm{CV}(\%)$ & ---- & 4,29 & 5.02 & 6,96 & 7,61 \\
\hline Média Geral & $\begin{array}{ll}--- \\
\end{array}$ & 14,5 & 3.1 & 1,4 & 1192,7 \\
\hline
\end{tabular}

** = Significativo a $1 \%$ de probabilidade ao teste F; * = Significativo a 5\% de probabilidade ao teste F;

${ }^{\mathrm{ns}}=$ Não significativo. Fonte: $\mathrm{O}$ autor.

Para a variável altura de planta foi verificado um aumento de cerca de $2,0 \mathrm{~cm}$ planta $^{-1}$ de rabanete entre as quantidades de 2,7 e 9,8 $\mathrm{t} \mathrm{ha}^{-1}$ de mata-pasto incorporado ao solo (Figuras 2a). Em relação aos períodos de incorporação observou-se comportamento semelhante às quantidades de mata-pasto, com uma média de $14,5 \mathrm{~cm}$ de altura de planta (Figuras 2b). A maior altura de planta possivelmente pode estar relacionada à disponibilidade de nitrogênio, elemento essencial no crescimento vegetal e responsável pela expansão foliar (Linhares et al., 2012). 
Figura 2 - Altura de planta sob diferentes quantidades (a) e períodos de incorporação (b) do mata-pasto ao solo. Catolé do Rocha-PB, UEPB, 2012 .
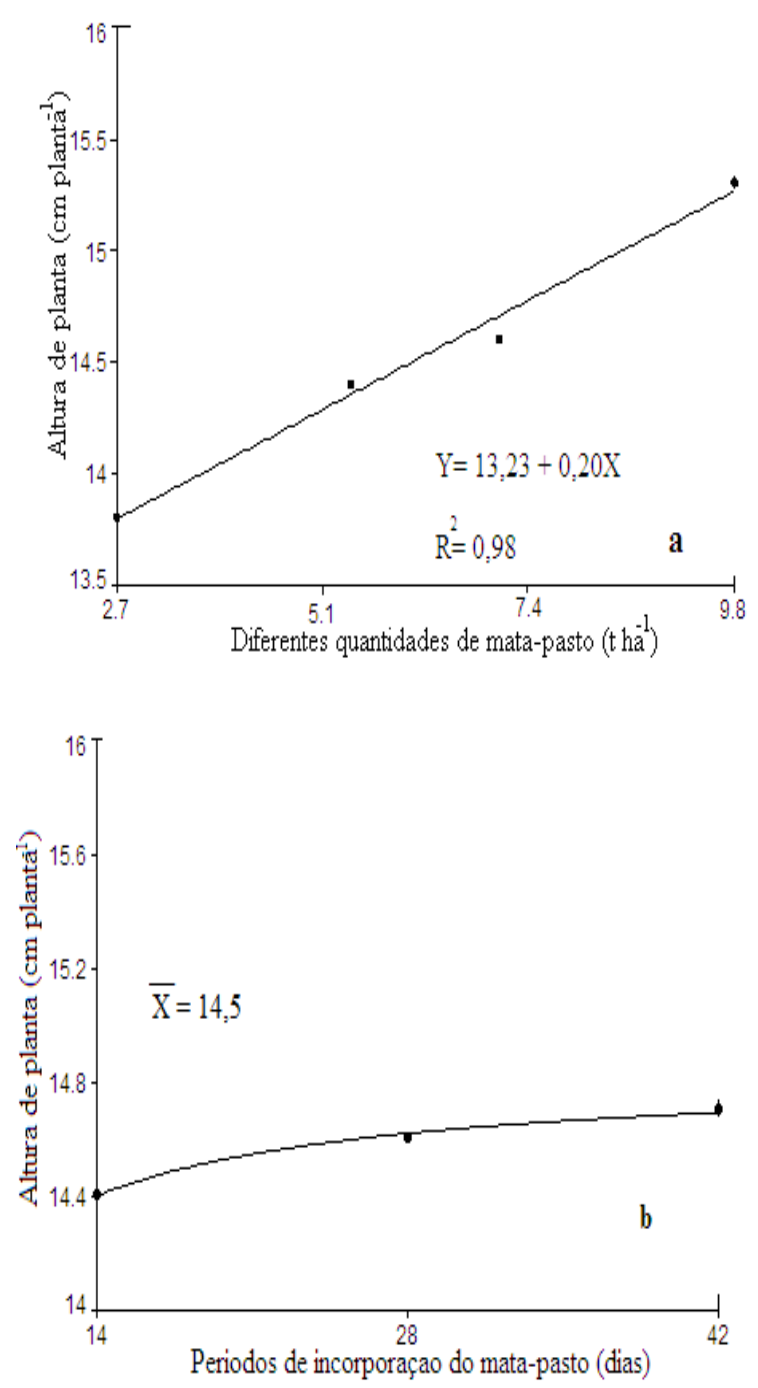

Fonte: $\mathrm{O}$ autor.

Em relação ao diâmetro de raiz do rabanete pode-se observar que a maior quantidade de mata-pasto incorporada ao solo contribuiu com o maior diâmetro médio $(3,4$ cm planta $^{-1}$ ) na quantidade de 9,8 $\mathrm{t} \mathrm{ha}^{-1}$ (Figura 3a). Em relação aos períodos de incorporação do mata-pasto ao solo, o mesmo influenciou de forma positiva na característica avaliada com valor médio de $3,30 \mathrm{~cm}$ para o período 14 dias, correspondendo há um acréscimo médio de $0,30 \mathrm{~cm}$ entre o maior período (42 dias) (Figura 3b). Esses diâmetros estão dentro do padrão de comercialização dessa hortaliça no mercado consumidor local.

Oliveira et al. (2005) observou valor médio de $3,5 \mathrm{~cm}$ planta $^{-1}$ para diâmetro de raiz do rabanete cultivado em condições de monocultivo. Resultados de 3,6 cm planta $^{-1}$ de diâmetro encontraram Salgado et al. (2006) trabalhando também com rabanete sob manejo orgânico. Assim como, Vittil et al. (2007) estudando adubação orgânica no rabanete, observaram no diâmetro $(3,7 \mathrm{~cm}$ planta $^{-1}$ ) quando na presença de $20 \mathrm{~g}$ de esterco bovino, um aumento de $44 \%$ em relação à testemunha. Esses resultados foram semelhantes ao obtido nessa pesquisa, demonstrando dessa forma a qualidade do mata-pasto em promover efeito positivo no desenvolvimento da raiz do rabanete. 
Figura 3 - Diâmetro de raiz de rabanete sob diferentes quantidades (a) e períodos de incorporação (b) do rabanete. Catolé do Rocha-PB, UEPB, 2012.
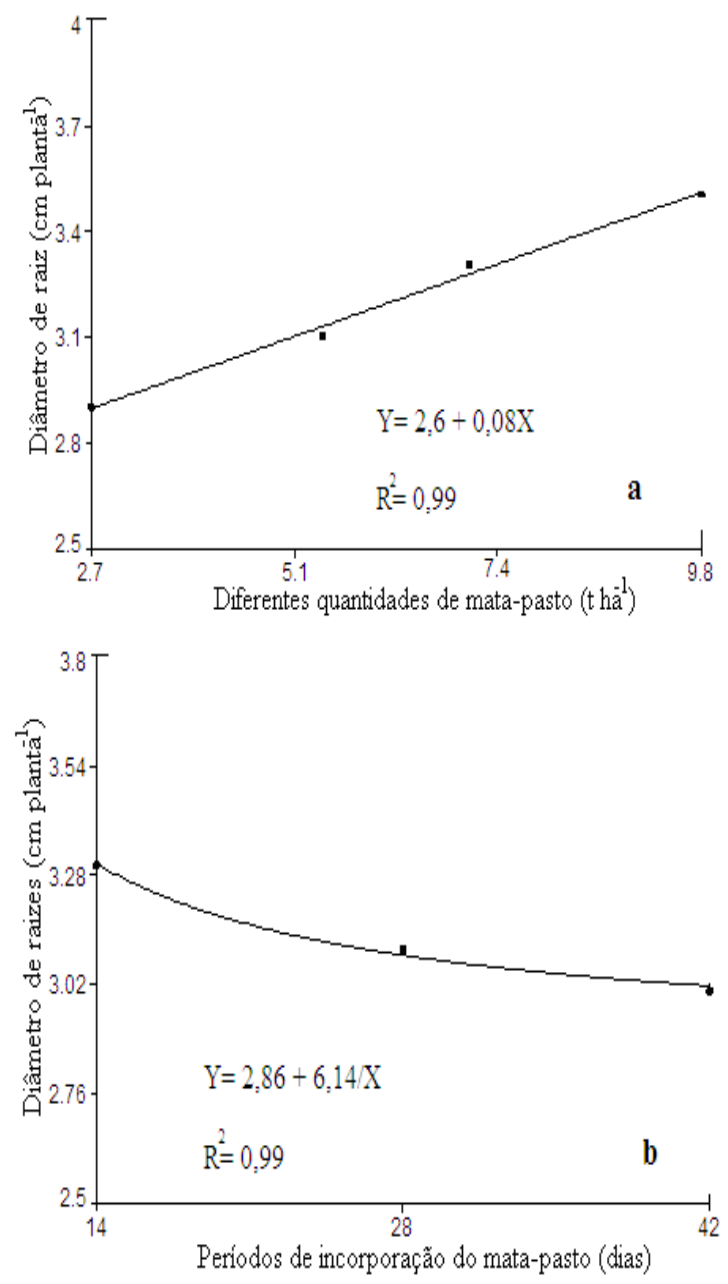

Fonte: O autor.

Em relação ao rendimento total, desdobrando os fatores estudados, a quantidade de $9,8 \mathrm{t} \mathrm{ha}{ }^{-1}$ não foi suficiente para promover um ponto de máximo, com valores médios de 1,$80 ; 1,80$ e $1,63 \mathrm{~kg} \mathrm{~m}^{-2}$ de canteiro, nos períodos de incorporação de 14; 28 e 42 dias, respectivamente (Figura 4). Comportamento semelhante observou-se no rendimento comercial, em que desdobrando os fatores estudados não se observou um ponto de máximo, com valores de 1,79; 1,78 e $1,39 \mathrm{~kg} \mathrm{~m}^{-2}$ de canteiro na quantidade de $9,8 \mathrm{t}$ $\mathrm{ha}^{-1}$ referente aos períodos de incorporação de 14, 28 e 42 dias, respectivamente (Figura 5). Por ser uma raiz, provavelmente esse comportamento se deva a disponibilidade de fósforo e potássio, elementos indispensáveis ao desenvolvimento das raízes. Oliveira et al. (2005) trabalhando com rabanete em consórcio com repolho com pré-cultivo de crotalária e adubado organicamente encontrou produtividade de $15360 \mathrm{~kg} \mathrm{ha}^{-1}$ no segundo ano de cultivo solteiro, sendo inferior ao referido trabalho, mesmo os autores utilizando a crotalária e a adubação orgânica.

Figura 4 - Desdobramento das quantidades de matapasto dentro dos períodos de incorporação no rendimento total de raízes de rabanete. Catolé do Rocha-PB, UEPB, 2012.

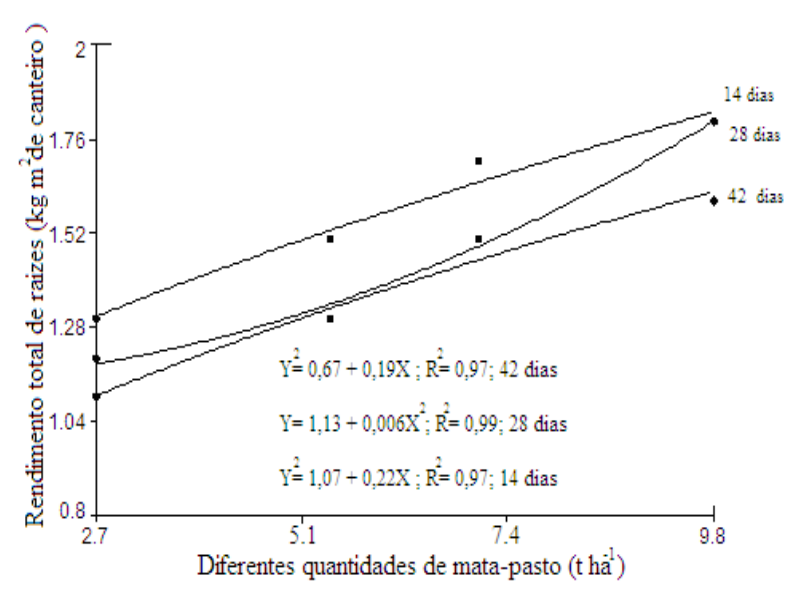

Fonte: $\mathrm{O}$ autor. 
Figura 5 - Desdobramento das quantidades de matapasto dentro dos períodos de incorporação no rendimento comercial de raízes de rabanete. Catolé do Rocha-PB, UEPB, 2012.

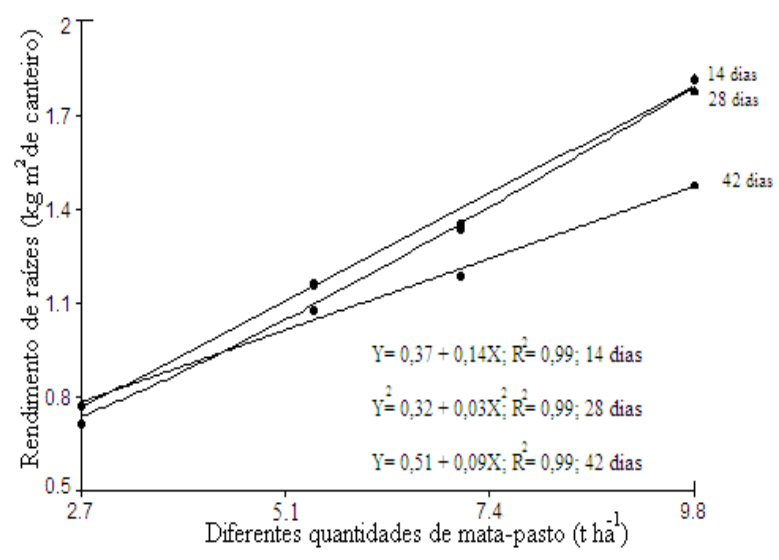

Fonte: $\mathrm{O}$ autor.

\section{CONCLUSÃO}

O melhor desempenho do rabanete foi observado na quantidade de $9,8 \mathrm{t} \mathrm{ha}^{-1}$ e no período de 14 dias de incorporação do matapasto ao solo.

O mata-pasto mostrou-se eficiente na avaliação do cultivo orgânico do rabanete.

\section{REFERÊNCIAS BIBLIOGRÁFICAS}

\section{BATISTA, M. A. V. Adubação verde na} produtividade, qualidade e rentabilidade de beterraba e rabanete. 2011. 123f. Tese (Doutorado em Agronomia: Fitotecnia) Universidade Federal Rural do Semi-Árido (UFERSA), Mossoró-RN.

CECÍLIO FILHO A. B.; MAY, A.

Produtividade das culturas de alface e rabanete em função da época de estabelecimento do consórcio, em relação a seus monocultivos. Horticultura Brasileira, v. 20, n. 3, p. 501-504, 2002.

COSTA C. C.; OLIVEIRA C. D.; SILVA C. J.; TIMOSSI P. C.; LEITE I. C. 2006. Crescimento, produtividade e qualidade de raízes de rabanete cultivadas sob diferentes fontes e doses de adubos orgânicos.

Horticultura Brasileira, v. 24, p. 118-122, 2006.

ESPINDOLA, J. A. A.; ALMEIDA, D. L.; GUERRA, J. G. M. Estratégias para utilização de leguminosas para adubação verde em unidades de produção agroecológica. Seropédica: Embrapa Agrobiologia, 2004. 24 p.

FAVERO, C; JUCKSCH, I; COSTA, L. M; ALVARENGA, R. C.; NEVES, J. C. L. Crescimento e acúmulo de nutrientes por plantas espontâneas e por leguminosas utilizadas para adubação verde. Revista Brasileira de Ciência do Solo, Viçosa, v.24, n. 1, p.171-177, 2000.

FERREIRA, C. J.; ZAMBON, F. R. A. Análise dos preços de rabanete no Estado de São Paulo. Horticultura Brasileira, v.22, n.2, 2004. 
GOMES, P. Adubos e Adubações. São

Paulo: Nobel S/A, 1984. p.56-65 (Biblioteca Rural).

ITO, H.; HORIE, H. A. A Chromatographic method for separating and identifying Intact 4-Methylthio-3-Butenyl Glucosinolate in Japanese Radish (Raphanus sativus L.).

Japan Agricultural Research Quarterly, v. 42, n. 2, p. 109-114, 2008.

JANDEL SCIENTIFIC. Table curve: curve fitting software. Corte Madera, CA: Jandel Scientific, 1991. 280 p.

KRONKA, S. N.; BANZATO, D. A. Estat: sistema para análise estatística. Funep: Jaboticabal, 1995. 243 p.

LINHARES, P. C. F.; SOUSA. A. J. P.; PEREIRA, M. F. S.; ALVES, R. F.; MARACAJÁ, P. B. Proporções de jitirana (Merremia aegyptia 1.) com flor-de-seda (Calotropis procera (ait.) R. Br.) no rendimento de coentro. Agropecuária Científica no Semiárido. v. 8, n. 4, p. 44-48, out - dez, 2012.

LINHARES, P. C. F.; SILVA, M. L.; SILVA, U. L.; SILVA, J. S.; BEZERRA; A. K. H. Velocidade e tempo de decomposição da jitirana incorporada na cultura do rabanete.

Revista Caatinga, v.22, n.2, p.213-217, abril/junho, 2009.
LINHARES, P. C. F; MARACAJÁ, P. B; LIMA, G. K. L. DE; BEZERRA NETO; F.; LIBERALINO FILHO; J. Resposta da rúcula (Eruca sativa Mill.) folha larga a adubação verde com jitirana (Ipomoea glabra L.) incorporada. Revista Verde, Mossoró, v. 3, n. 2, p. 72.- 77, 2008. MINAMI, K.; CARDOSO, A. I. I.; COSTA, F.; DUARTE, R. Efeito do espaçamento sobre a produção em rabanete. Bragantia, v. 57, p. 169-173, 1998.

NOVAIS, R. F; ALVAREZ, V. V. H.; BARROS, N. F; FONTES, R. L. F; CANTARUTI, R. B.; NEVES, J. C. L. Fertilidade do solo. In: MEURER, E. J. Fatores que influenciam o crescimento e o desenvolvimento das plantas. Viçosa-MG: SBCS, p. 65-90, 2007.

OLIVEIRA, F.L.; RIBAS, R.G.T.; JUNQUEIRA, R.M.; PADOVAN, M.P.; GUERRA, J.G.M.; ALMEIDA, D.L.; RIBEIRO, R.L.D. Desempenho do consórcio entre repolho e rabanete com pré-cultivo de crotalária, sob manejo orgânico. Horticultura Brasileira, Brasília, v.23, n.2, p.184-188, abrjun, 2005.

SALGADO, A. S.; GUERRA, J. G. M.; ALMEIDA, D. L.; RIBEIRO, R. L. D.; ESPINOLA, J. A. A.; SALGADO, J. A. A. Consórcios alface-cenoura e alface-rabanete sob manejo orgânico. Pesquisa 
Agropecuária Brasileira, Brasília, v. 41, n.

7, p. 1141-1147, 2006.

SILVA, F. C. da. Manual de análises químicas de solos, plantas e fertilizantes.

Brasília: Embrapa Comunicação para a

Transferência de Tecnologia, 1999. 370p.
VITTIL, M. R.; VIDAL, M. B.; MORSELLI, T. B. G. A.; FARIA, J. L. C. Resposta do rabanete a adubação orgânica em ambiente protegido. Revista Brasileira de Agroecologia, Curitiba, v. 2, n. 1, p. 45-53, 2007. 